\title{
Optimising Clinical Trial Design for Proof of Neuroprotection in Acute Ischaemic Stroke: The SAINT Clinical Trial Programme
}

\author{
Stephen Davis \\ Royal Melbourne Hospital, University of Melbourne, Australia
}

\author{
Key Words \\ Acute ischaemic stroke - Neuroprotection • \\ NXY-059 · Stroke Therapy Academic Industry \\ Roundtable (STAIR) · Stroke Acute Ischaemic NXY-059 \\ Treatment (SAINT) · Clinical trial programme
}

\begin{abstract}
The development of effective therapies for acute ischaemic stroke has proven to be a challenging task. The only approved therapy for acute ischaemic stroke remains intravenous recombinant tissue plasminogen activator initiated within $3 \mathrm{~h}$ of stroke onset, following a CT scan to exclude intracerebral haemorrhage. Many other therapies have been evaluated in Phase III clinical trials, including more than 50 neuroprotective agents, but the results have either been inconclusive or negative. These trials have provided valuable lessons for the design of future studies in acute ischaemic stroke, including the importance of adequate testing in preclinical studies, time to treatment from symptom onset, target dose, patient selection, sample size and the outcome measures used. These key criteria have been captured in the Stroke Therapy Academic Industry Roundtable (STAIR) recommendations for the preclinical and clinical development of acute stroke therapies. NXY-059 is a novel free radical-trapping neuroprotectant that reduces infarct size and preserves brain function in animal models of acute ischaemic stroke. It is one of the first compounds to have
\end{abstract}

progressed to Phase III clinical trials, having fulfilled the STAIR recommendations for the preclinical development of neuroprotective agents. The efficacy and safety of NXY-059 in patients with acute ischaemic stroke is currently being evaluated in the Stroke Acute Ischaemic NXY-059 Treatment (SAINT) clinical trial programme, which was designed in accordance with the STAIR clinical recommendations. The final results from the first of these studies, SAINT I, have recently been reported.

Copyright (C) 2006 S. Karger AG, Basel

\section{Introduction}

The development of acute ischaemic stroke therapy has proven to be a daunting task. Important advances to date have included proof of the benefits of organised care in stroke units $[1,2]$, recognition of the modest benefits of aspirin in acute ischaemic stroke [3-5], and approval of recombinant tissue plasminogen activator (rt-PA) for acute ischaemic stroke by the US Food and Drug Administration (FDA) [6]. Other agents aimed at reperfusion following acute ischaemic stroke, such as intra-arterial prourokinase [7], intravenous ancrod [8] and abciximab [9] have shown promise but have not received marketing approval. Another thrombolytic agent, desmoteplase, is undergoing further trials after a positive proof of concept study [10]. Most recently, the Merci Retriever system was approved by the FDA for clot removal from the intracra-

\section{KARGER \\ Fax +4161306 1234 E-Mail karger@karger.ch} www.karger.com
(C) $2006 \mathrm{~S}$. Karger AG, Basel

$1015-9770 / 06 / 0227-0018 \$ 23.50 / 0$

Accessible online at: www.karger.com/ced
Stephen Davis

Department of Neurology

Royal Melbourne Hospital, University of Melbourne

Parkville Vic 3050, Melbourne (Australia)

Tel. +61 39342 8448, Fax +6139342 8427, E-Mail stephen.davis@mh.org.au 
Table 1. Summary of failed trials of neuroprotective agents. Adapted from Beresoford et al, 2003 [19]

\begin{tabular}{lll}
\hline Product & Mechanism & Outcome \\
\hline Nimodipine & Calcium channel blocker & Mixed effects on outcome. Not approved \\
Fosphenytoin & Sodium channel blocker & Phase III trial halted due to lack of efficacy \\
BMS-204352 & Potassium channel opener & Phase III trial failed. A second trial is being considered \\
Selfotel & NMDA antagonist & Preliminary results showed no efficacy in Phase III trials \\
Eliprodil & NMDA polyamine site blocker & Phase III trials abandoned \\
Aptiganel & NMDA channel blocker & Preliminary results showed no efficacy in Phase III trials \\
Gavestinel & Glycine antagonist & Preliminary results showed no efficacy in Phase III trials \\
Tirilazad & Lipid peroxidation inhibitor & Review of six trials showed that it worsened outcome \\
Lubeluzole & Ion channel and nitric oxide blocker & No efficacy in Phase III trial \\
Enlimomab & Murine anti-ICAM-1 antibody & Worsened outcome \\
UK-279,276 & Neutrophil inhibitory factor & Unsuccessful Phase II trials \\
Trafermin & Growth factor & Phase II/III trials halted due to lack of efficacy \\
Clomethiazole & GABA agonist & Phase III trials halted due to lack of efficacy \\
\hline Repinotan & 5-HT 1 A receptor agonist & Disappointing results in Phase IIb trial [21] \\
ONO-2506 & Astrocyte-modulating agent & Unfavourable interim analysis of Phase II trial \\
\hline \multirow{2}{*}{ NMDA = N-methyl-d-aspartate; GABA = gamma-aminobutyric acid. } \\
\hline
\end{tabular}

nial vasculature in ischaemic stroke, although not yet proven in pivotal trials [11].

Over 50 neuroprotective agents have also been tested in randomised, controlled trials of acute ischaemic stroke [12], but none have demonstrated unequivocal efficacy. The Stroke Therapy Academic Industry Roundtable (STAIR) has developed recommendations for the preclinical and clinical evaluation of acute ischaemic stroke therapies to optimise the potential for successful translation from animal models to human stroke [13-16]. One of the most promising neuroprotective agents developed to date, NXY-059, is being evaluated in the Stroke Acute Ischaemic NXY-059 Treatment (SAINT) clinical trial programme, which was designed in accordance with the STAIR criteria.

\section{Neuroprotective Agents in Acute Ischaemic Stroke}

Pharmacological therapy in acute ischaemic stroke can be divided into two broad classes: restoring cerebral blood flow (reperfusion) and therapies aimed at modifying components of the neurotoxic cascade that follows ischaemia (neuroprotection). Cerebral ischaemia triggers the pathological pathways of the ischaemic cascade that cause cell death in the ischaemic core and neuronal cell injury in the ischaemic penumbra [17]. By interfering with this ischaemic cascade, neuroprotective strategies aim to preserve viable brain cells in the ischaemic penumbra, thereby aiding recovery from stroke $[17,18]$. The target for both reperfusion and neuroprotective strategies is the salvage of ischaemic penumbra, with limitation of infarct volume and hence improved outcomes.

Approaches to neuroprotection have included modulation of calcium, sodium and potassium channels, glutamate release/N-methyl-d-aspartate (NMDA) receptor antagonists, free radical scavengers, nitric oxide-related intervention, anti-inflammatory agents, growth factors, gamma-aminobutyric acid (GABA) agonists and serotonin $\left(5-\mathrm{HT}_{1 \mathrm{~A}}\right)$ receptor agonists [19].

Although a broad range of neuroprotective strategies has been shown to reduce infarct size and improve functional outcome measures in animal stroke models [20], none have proven unequivocally beneficial in Phase III efficacy trials. This failed translation of neuroprotective agents is summarised in table 1 [19]. Most recently, clinical development of the $5-\mathrm{HT}_{1 \mathrm{~A}}$ receptor agonist repinotan for the treatment of acute ischaemic stroke was halted following the disappointing results of a Phase IIb study [21], while a Phase II study of the astrocyte-modulating agent ONO-2506 in acute ischaemic stroke was terminated in the US following an unfavourable interim analysis [22].

The failure of neuroprotective agents in Phase III efficacy trials has been attributed to multiple factors relat- 
ing to inadequate preclinical data, unfavourable compound characteristics and poor clinical trial design [23]. The animal models of stroke used to evaluate neuroprotective agents have usually involved young healthy rodents, rather than elderly animals that are more representative of typical human stroke populations that may suffer from multiple co-morbid conditions. Moreover, in contrast to the human brain, the rodent brain contains only a small amount of white matter and it is likely that the mechanisms of ischaemic damage differ between white and grey matter [24]. The heterogeneity and complexity of human stroke compared with animal infarct models is likely to be another factor [25].

Poor design of the clinical Phase III trials of neuroprotective agents may also have contributed to the lack of evidence for the efficacy of many novel compounds that have been investigated [23]. The only therapy proven to be effective in acute ischaemic stroke, rt-PA, has a treatment window of just $3 \mathrm{~h}$ [6]. In contrast, most previous trials of neuroprotective agents have allowed enrolment 6 to $8 \mathrm{~h}$ or more following stroke onset, despite preclinical evidence of much shorter time windows [15]. Many trials have enrolled patients with stroke severities that render them uninformative with regard to treatment effect. For example, patients with mild stroke are likely to do well, while patients with severe stroke are likely to do poorly, irrespective of intervention. Additionally, most studies of neuroprotective agents have been underpowered and so were unable to detect any modest, yet clinically significant benefits of the study agent [26]. This is particularly important given that the benefits of neuroprotection are likely to be considerably smaller than those observed in trials of reperfusion [27], so that sample size is an important issue.

In some trials, study agents have been tested at doses below those shown to be neuroprotective in animal models because of dose-limiting side effects, such as psychoactive effects, QT prolongation or liver function test abnormalities [28]. Two large Phase III trials of the competitive NMDA antagonist selfotel were terminated prematurely because of an apparent lack of clinical efficacy [29]. In these trials, selfotel was administered at lower doses than those required to achieve neuroprotective plasma concentrations in animal stroke models, because of adverse effects. Finally, the use of outcome measures not sufficiently sensitive to assess modest but clinically relevant differences in functional outcome may also have contributed to the large number of trial failures [30].
Table 2. The STAIR recommendations for standards regarding preclinical neuroprotective drug development [14]

Adequate dose-response studies should be conducted with serum concentrations measured to define minimally and maximally effective doses

Time-window studies to confirm efficacy are required

Physiological monitoring should be undertaken

Randomised, blinded studies that give reproducible effects should be conducted, involving at least one independent laboratory

Both infarct volume and functional response should be assessed, including short- and long-term assessment

Efficacy should be evaluated in both transient and permanent middle cerebral artery occlusion rat models

For novel, first-in-class agents, studies in larger species/primates are required to confirm efficacy

Studies should be published in peer-reviewed journals

\section{The STAIR Criteria}

The preclinical STAIR recommendations for the evaluation of neuroprotective agents (table 2) [14] emphasise the importance of rigorously testing these agents in preclinical stroke models designed to investigate dose ranges, the time window of treatment effects, histological and functional outcomes, sustained treatment effects and safety, before progressing to Phase III efficacy trials. It is also recommended that first-in-class agents be investigated in larger species/primate models, after demonstration of a biological action in rodents. These recommendations were extended in 2003 to include the extent of histological protection, subcortical protection, white matter protection, the length of treatment and efficacy as monotherapy [31].

The clinical guidelines developed by the STAIR advocate that neuroprotective agents be administered to patients using analogous conditions shown to produce significant histological and functional protection in animals [15]. Hence, patients should be enrolled as soon as possible after stroke onset to match the time window proven in animal models. The doses used in humans should produce plasma levels shown to be neuroprotective in animal models. Limiting enrolment to patients with moderate baseline deficits (e.g. National Institutes of Health Stroke Scale [NIHSS] scores of 7-22) would be expected to enhance the probability of detecting a clinical benefit, given 
Fig. 1. Mean (SD) unbound plasma concentrations of NXY-059 at end of loading infusion and at steady state (approximately $72 \mathrm{~h}$ ) after either 420 or $844 \mathrm{mg} / \mathrm{h}$ versus target concentrations associated with neuroprotection in rat models of transient and permanent focal ischaemia [38]. MCAO = Middle cerebral artery occlusion.

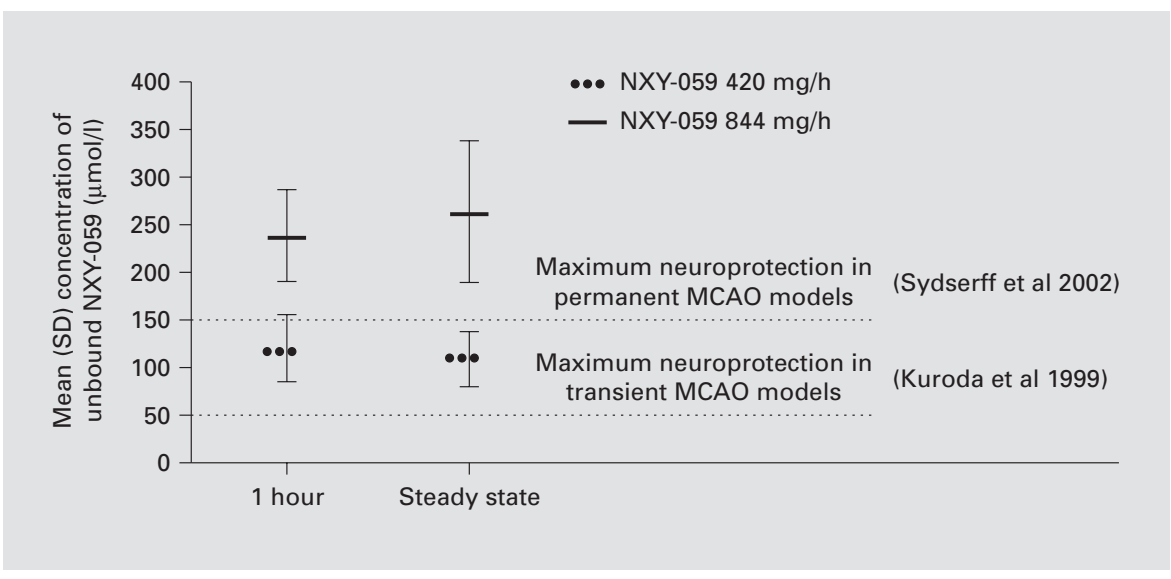

the high placebo response in patients with mild stroke and the greater difficulty in attaining improvement in those severely affected. Additionally, a meaningful and reliable outcome measure should be selected. A global statistical approach is recommended, whereby the treatment effect is measured using multiple pre-defined outcome measures. As discussed previously, the trial should be powered with an adequate sample size to detect any small, yet clinically significant, benefits of the study agent [32].

\section{NXY-059: A Novel Neuroprotectant}

NXY-059 is a novel free radical-trapping neuroprotectant that acts at several points in the ischaemic cascade. It has been shown to be neuroprotective in rat models of transient and permanent focal cerebral ischaemia [3335 ] and to reduce infarct volume and improve functional recovery in a primate model of permanent focal ischaemia [36]. NXY-059 is the first compound to have progressed to Phase III clinical efficacy trials on the basis of having met all the benchmark STAIR preclinical criteria (table 2).

\section{Tolerability and Efficacy of NXY-059: Results of a Dose-Escalation Study}

An initial clinical study demonstrated that NXY-059 was well tolerated by stroke patients at plasma concentrations that provided neuroprotection in a rat model of transient focal ischaemia ( 8 to $40 \mu \mathrm{mol} / \mathrm{l}$ ) [37]. A further Phase IIa study investigated the tolerability of NXY-059 at the higher plasma concentrations (50 to $150 \mu \mathrm{mol} / \mathrm{l}$ ) needed to achieve neuroprotection in the rat model of permanent focal ischaemia [38]. In this double-blind, dose-escalation study, 135 patients with acute stroke were randomised to NXY-059 at a loading dose of $915 \mathrm{mg}$ over $1 \mathrm{~h}$ followed by $420 \mathrm{mg} / \mathrm{h}$ for $71 \mathrm{~h}, \mathrm{NXY}-059$ at $1,820 \mathrm{mg}$ for $1 \mathrm{~h}$ followed by $844 \mathrm{mg} / \mathrm{h}$ for $71 \mathrm{~h}$, or placebo. NXY059 was well tolerated at, and above, concentrations shown to be neuroprotective in the rat model. The unbound NXY-059 plasma concentration at steady state in the high-dose group $(260 \mu \mathrm{mol} / \mathrm{l})$ exceeded the concentration needed to achieve neuroprotection in the rat model (fig. 1) and in a subsequent primate model of permanent focal ischaemia [36].

\section{The SAINT Clinical Trial Programme}

The efficacy and safety of NXY-059 in patients with acute ischaemic stroke is being evaluated in the SAINT clinical trial programme. The trial programme comprises two large double-blind, randomised, placebo-controlled, multi-centre Phase III studies, SAINT I and SAINT II. SAINT I was conducted at more than 150 centres and enrolled approximately 1,700 patients in Europe, Australia, South Africa and Asia [39]. SAINT II is also an international trial, with an analogous protocol and has increased the sample size to 3,200 patients.

The two trials were designed in accordance with the STAIR criteria (table 3) to assess the efficacy of intravenous NXY-059 on disability and neurological recovery and to evaluate safety when administered within 6 hours of stroke onset [40]. Acute ischaemic stroke patients with a NIHSS score of $\geq 6$ and limb weakness are eligible for study inclusion. Given that animal model data have shown that NXY-059 provides significant neuroprotective effects at 4 to $5 \mathrm{~h}$, with trends at $6 \mathrm{~h}[33,34,36]$, the SAINT clinical trials were designed to support regulatory approval for a 6-h treatment window, thereby providing 
Table 3. Factors to be considered when designing Phase III trials in acute ischaemic stroke and corresponding features of the SAINT trials

\begin{tabular}{|c|c|c|}
\hline Consideration & Rationale & Design features of the SAINT trials \\
\hline Patient selection & $\begin{array}{l}\text { The likelihood of detecting clinical benefit } \\
\text { is increased if enrolment is limited to } \\
\text { patients with moderate baseline deficits }\end{array}$ & $\begin{array}{l}\text { Inclusion criteria state: NIHSS score } \geq 6 \\
\text { at baseline }\end{array}$ \\
\hline Time to treatment & $\begin{array}{l}\text { Enrolment as soon as possible after } \\
\text { stroke onset and within the time window } \\
\text { observed in animal models }\end{array}$ & $\begin{array}{l}\text { Forced stratification means that a } \\
\text { significant number of patients will be } \\
\text { treated within } 4 \mathrm{~h}\end{array}$ \\
\hline Dose & $\begin{array}{l}\text { Doses used should attain plasma levels } \\
\text { shown to be neuroprotective in animal } \\
\text { models }\end{array}$ & $\begin{array}{l}\text { Doses selected attain exposure shown to } \\
\text { be neuroprotective in primate and rodent } \\
\text { models of permanent ischaemia. No } \\
\text { dose-limiting adverse events identified }\end{array}$ \\
\hline Endpoint selection & $\begin{array}{l}\text { Outcome measures, appropriate to the } \\
\text { expected clinical benefits, and the inclusion } \\
\text { of a global outcome scale should be } \\
\text { selected. Both physician- and patient-rated } \\
\text { scales should be used }\end{array}$ & $\begin{array}{l}\text { A range of physician- and patient-rated } \\
\text { endpoints used to fully quantify the } \\
\text { clinical benefit of NXY-059 treatment }\end{array}$ \\
\hline Sample size & $\begin{array}{l}\text { The sample size should ensure sufficient } \\
\text { power to detect small but clinically } \\
\text { significant differences in treatment effect }\end{array}$ & $\begin{array}{l}\text { Sample size calculation based on the } \\
\text { assumption of a clinically relevant } \\
\text { treatment effect equivalent to a common } \\
\text { odds ratio of } 1.3 \text { ( } 90 \% \text { power; } 5 \% \\
\text { two-sided significance) }\end{array}$ \\
\hline
\end{tabular}

NIHSS = National Institutes of Health Stroke Scale.

treatment for a broad patient group. To enhance the probability of success for the trial programme, a novel approach is used to obtain a mean treatment window $<4 \mathrm{~h}$ (as used in rat and primate models of permanent focal ischaemia $[34,36])$ while ensuring a distribution of patients up to $6 \mathrm{~h}$. Forced stratification is used to ensure that the average time until the start of study drug is $<4 \mathrm{~h}$ at each centre. Hence, at each site, the first randomised patient is required to have a time to start of study drug of $<4 \mathrm{~h}$; the target time for each subsequent patient is supplied by an interactive voice response system to maintain an average time of $<4 \mathrm{~h}$.

The dosing regimen $(2,270 \mathrm{mg}$ for $1 \mathrm{~h}$ followed by $960 \mathrm{mg} / \mathrm{h}$ for $71 \mathrm{~h}$ ) was selected on the basis of the results of the Phase IIb study discussed earlier [38]. The primary outcome measure is the modified Rankin scale (mRS) [41] at 90 days or last rating, analysed across the whole distribution of scores, adjusted for stratification variables. It was prespecified that the analysis of the efficacy outcomes was ordered hierarchically and formal statistical testing was performed only if the preceding endpoint was significant. The highest ranked endpoint in the hierarchy after the mRS was for the SAINT I trial the change from baseline in the NIHSS score [42], termed co-primary in the protocol. Further secondary outcomes include functional outcome assessed with the Barthel Index [43], impact on daily activities (using the patient-rated Stroke Impact Scale) [44], and quality of life (using the EQ-5D patient-rated instrument) [45]. Training and certification in the mRS and NIHSS has been conducted to ensure that the scales are used effectively and consistently within the trials. The sample size calculation was based on the assumption of a clinically relevant treatment effect equivalent to a common odds ratio of 1.3 (90\% power, $5 \%$ two-sided significance). NXY-059 significantly improved the overall distribution of the mRS disability score compared to placebo $(p=0.038)$ in the SAINT I trial [39]. The incidence and profile of adverse events for NXY-059 was comparable to placebo. 


\section{Conclusions}

The many previous failed trials of neuroprotective strategies have provided valuable lessons for the design of future studies in acute ischaemic stroke. All the key criteria embodied in the STAIR recommendations for the preclinical and clinical development of acute stroke therapies have been adopted for the evaluation of NXY-059. These include the proof of a potent neuroprotective action in rodent transient and permanent stroke models; efficacy in a primate model in both histological and functional outcomes; safety with successful achievement of neuroprotective plasma concentrations in human stroke matching these preclinical models; and design of two piv- otal clinical trials with appropriate sample sizes and optimal trial design to test the safety and efficacy of NXY059.

Results from SAINT I demonstrate that NXY-059 significantly improved the overall distribution of the $\mathrm{mRS}$ scores compared to placebo, with reduction in disability at 90 days after treatment within $6 \mathrm{~h}$ of stroke onset.

\section{Acknowledgements}

I thank Dr Louise Picken, from Complete Medical Communications, who provided medical writing support on behalf of AstraZeneca.

\section{References}

1 Stroke Unit Trialists' Collaboration: How do stroke units improve patient outcomes? A collaborative systematic review of the randomized trials. Stroke 1997;28:2139-2144.

-2 Stroke Unit Trialists' Collaboration: Collaborative systematic review of the randomised trials of organised inpatient (stroke unit) care after stroke. BMJ 1997;314:1151-1159.

-3 CAST (Chinese Acute Stroke Trial) Collaborative Group: CAST: randomised placebo-controlled trial of early aspirin use in 20000 patients with acute ischaemic stroke. Lancet 1997;349:1641-1649.

-4 International Stroke Trial Collaborative Group: The International Stroke Trial (IST): a randomised trial of aspirin, subcutaneous heparin, both, or neither among 19435 patients with acute ischaemic stroke. Lancet 1997;349: 1569-1581.

-5 Chen ZM, Sandercock P, Pan HC, Counsell C, Collins R, Liu LS, Xie JX, Warlow C, Peto R, on behalf of the CAST and IST collaborative groups: Indications for early aspirin use in acute ischemic stroke. A combined analysis of 40000 randomized patients from the chinese acute stroke trial and the international stroke trial. Stroke 2000;31:1240-1249.

-6 NINDS rt-PA Stroke Study Group: Tissue plasminogen activator for acute ischemic stroke. The National Institute of Neurological Disorders and Stroke rt-PA Stroke Study Group. N Engl J Med 1995;333:1581-1587.

-7 Furlan A, Higashida R, Wechsler L, Gent M, Rowley H, Kase C, Pessin M, Ahuja A, Callahan F, Clark WM, Silver F, Rivera F, for the PROACT investigators: Intra-arterial prourokinase for acute ischemic stroke. The PROACT II study: a randomized controlled trial. JAMA 1999;282:2003-2011.
-8 Sherman DG, Atkinson RP, Chippendale T, Levin KA, Ng K, Futrell N, Hsu CY, Levy DE, for the STAT Participants: Intravenous ancrod for treatment of acute ischemic stroke. The STAT study: a randomized controlled trial. JAMA 2000;283:2395-2403.

-9 Abciximab Emergent Stroke Treatment Trial (AbESTT) Investigators: Emergency administration of abciximab for treatment of patients with acute ischemic stroke: results of a randomized phase 2 trial. Stroke 2005;36:880 890.

10 Hacke W, Albers G, Al-Rawi Y, Bogousslavsky J, Davalos A, Eliasziw M, Fischer M, Furlan A, Kaste M, Lees KR, Soehngen M, Warach S, for the DIAS Study Group: The Desmoteplase in Acute Ischemic Stroke Trial (DIAS): a phase II MRI-based 9-hour window acute stroke thrombolysis trial with intravenous desmoteplase. Stroke 2005;36:66-73.

11 Felten RP, Ogden NR, Pena C, Provost MC, Schlosser MJ, Witten CM: The Food and Drug Administration medical device review process: clearance of a clot retriever for use in ischemic stroke. Stroke 2005;36:404-406.

12 Kidwell CS, Liebeskind DS, Starkman S, Saver JL: Trends in acute ischemic stroke trials through the 20th century. Stroke 2001;32: 1349-1359.

13 Fisher M, for the Stroke Therapy Academic Industry Roundtable: Recommendations for advancing development of acute stroke therapies. Stroke Therapy Academic Industry Roundtable 3. Stroke 2003;34:1539-1546.

14 Stroke Therapy Academic Industry Roundtable (STAIR): Recommendations for standards regarding preclinical neuroprotective and restorative drug development. Stroke 1999;30: 2752-2758.

15 Stroke Therapy Academic Industry Roundtable II (STAIR-II): Recommendations for clinical trial evaluation of acute stroke therapies. Stroke 2001;32:1598-1606.
16 Fisher M, Albers GW, Donnan GA, Furlan AJ, Grotta JC, Kidwell CS, Sacco RL, Wechsler LR: Enhancing the development and approval of acute stroke therapies: Stroke Therapy Academic Industry Roundtable. Stroke 2005;36: 1808-1813.

17 Dirnagl U, Iadecola C, Moskowitz MA: Pathobiology of ischaemic stroke: an integrated view. Trends Neurosci 1999;22:391-397.

18 Fisher M: The ischemic penumbra: identification, evolution and treatment concepts. Cerebrovasc Dis 2004; 17(suppl 1):1-6.

19 Beresford IJM, Parsons AA, Hunter AJ: Treatments for stroke. Expert Opin Emerging Drugs 2003; 8:103-122.

20 Fisher M, Schaebitz W: An overview of acute stroke therapy. Past, present, and future. Arch Intern Med 2000;160:3196-3206.

21 Bayer Global. 2005. (Accessed April, 2005, at Bayer Global).

22 ONO Pharmaceutical Co Ltd. 2005. (Accessed May, 2005, at ONO Pharmaceutical Co Ltd).

23 Fisher M, Brott TG: Emerging therapies for acute ischemic stroke. New therapies on trial. Stroke 2003;34:359-361.

24 Yam PS, Patterson J, Graham DI, Takasago T, Dewar D, McCulloch J: Topographical and quantitative assessment of white matter injury following a focal ischaemic lesion in the rat brain. Brain Res Brain Res Protoc 1998;2: 315-322.

25 Davis SM, Donnan GA: Neuroprotection: establishing proof of concept in human stroke. Stroke 2002;33:309-310.

26 Samsa GP, Matchar DB: Have randomized controlled trials of neuroprotective drugs been underpowered? An illustration of three statistical principles. Stroke 2001;32:669-674.

- 27 Heiss WD, Thiel A, Grond M, Graf R: Which targets are relevant for therapy of acute ischemic stroke? Stroke 1999;30:1486-1489. 
28 Cheng YD, Al-Khoury L, Zivin JA: Neuroprotection for ischemic stroke: two decades of success and failure. Neurorx 2004;1:36-45.

-29 Davis SM, Lees KR, Albers GW, Diener HC, Markabi S, Karlsson M, Norris J: Selfotel in acute ischemic stroke: possible neurotoxic effects of an NMDA antagonist. Stroke 2000;31: 347-354.

- 30 Ovbiagele B, Kidwell CS, Starkman S, Saver JL: Neuroprotective agents for the treatment of acute ischemic stroke. Curr Neurol Neurosci Rep 2003;3:9-20.

- 31 Green AR, Odergren T, Ashwood T: Animal models of stroke: do they have value for discovering neuroprotective agents? Trends Pharmacol Sci 2003;24:402-408.

- 32 Wahlgren NG, Ahmed N.Neuroprotection in cerebral ischaemia: facts and fancies - the need for new approaches. Cerebrovasc Dis 2004; 17(suppl 1):153.

33 Kuroda S, Tsuchidate R, Smith ML, Maples KR, Siesjö BK: Neuroprotective effects of a novel nitrone, NXY-059, after transient focal cerebral ischemia in the rat. J Cereb Blood Flow Metab 1999;19:778-787.

34 Sydserff SG, Borelli AR, Green AR, Cross AJ: Effect of NXY-059 on infarct volume after transient or permanent middle cerebral artery occlusion in the rat; studies on dose, plasma concentration and therapeutic time window. Br J Pharmacol 2002;135:103-112.
35 Zhao Z, Cheng M, Maples KR, Ma JY, Buchan AM: NXY-059, a novel free radical trapping compound, reduces cortical infarction after permanent focal cerebral ischemia in the rat. Brain Res 2001;909:46-50.

36 Marshall JWB, Cummings RM, Bowes LJ, Ridley RM, Green AR: Functional and histological evidence for the protective effect of NXY-059 in a primate model of stroke when given 4 hours after occlusion. Stroke 2003;34: 2228-2233.

37 Lees KR, Sharma AK, Barer D, Ford GA, Kostulas V, Cheng Y-F, Odergren T, for the SANXY-0003 Investigators: Tolerability and pharmacokinetics of the nitrone NXY-059 in patients with acute stroke. Stroke 2001;32: 675-680.

38 Lees KR, Barer D, Ford GA, Hacke W, Kostulas V, Sharma AK, Odergren T, for the SANXY-0004 Investigators: Tolerability of NXY-059 at higher target concentrations in patients with acute stroke. Stroke 2003;34: 482-487.
39 Lees KR, Zivin JA, Ashwood T, Davalos A, Davis SM, Diener HC, Grotta J, Lyden P, Shuaib A, Hardemark HG, Wasiewski WW: NXY-059 for acute ischemic stroke. N Engl J Med 2006;354:588-600.

40 Diener HC, Davalos A, Davies SM, Grotta J, Lees KR, Lyden P, Shuaib A, Zivin JA, Ashwood T, Wasiewski W, for the SAINT I Trial Investigators: SAINT I: A double-blind, multicentre, placebo-controlled study to assess the efficacy and safety of NXY-059 in acute ischaemic stroke. Eur J Neurol 2005, in press.

41 van Swieten JC, Koudstaal PJ, Visser MC, Schouten HJ, Van Gijn J: Interobserver agreement for the assessment of handicap in stroke patients. Stroke 1988;19:604-607.

- 42 Brott T, Adams HP, Jr., Olinger CP, Marler JR, Barsan WG, Biller J, Spilker J, Holleran R, Eberle R, Hertzberg V: Measurements of acute cerebral infarction: a clinical examination scale. Stroke 1989;20:864-870.

43 Mahoney FI, Barthel DW: Functional evaluation: the Barthel Index. Md State Med J 1965; 14:61-65.

-44 Duncan PW, Wallace D, Studenski S, Lai SM, Johnson D: Conceptualization of a new strokespecific outcome measure: the stroke impact scale. Top Stroke Rehabil 2001;8:19-33.

45 Rabin R, de Charro F: EQ-5D: a measure of health status from the EuroQol Group. Ann Med 2001;33:337-343. 